\title{
Body Habitus Artifact
}

National Cancer Institute

\section{Source}

National Cancer Institute. Body Habitus Artifact. NCI Thesaurus. Code C87030.

Artifacts related to the physique or body build of the patient. 